\title{
Analysis of Development Costs and Value-Added Accounting Information Systems on Road and Inpatient Services at Cribs and Gebang Medika Clinic
}

\author{
Analisis Biaya Pengembangan dan Value-Added Sistem Informasi Akuntansi Pelayanan \\ Rawat Jalan dan Rawat Inap pada Rumah Bersalin dan Klinik Gebang Medika
}

\author{
Hapsari Widayani \\ hwidayani@gmail.com \\ Universitas Indraprasta PGRI
}

\begin{abstract}
The purpose of this study was to analyze the processes and procedures for accounting information systems for outpatient and inpatient services at Gebang Medika's Maternity Hospital and Clinic. In addition, it is also used to analyze procurement costs and how to create value-added accounting information systems for outpatient and inpatient services at the Maternity Hospital and Gebang Medika Clinic. The data collection method was carried out by direct observation to the research object, namely the Maternity Hospital and the Gebang Medika Clinic. The data used are primary data. This study uses value-added analysis and its design uses a web technology base and MySQL for its database.The results in this study are outpatient and inpatient service procedures at this clinic starting from the patient coming to the clinic then carrying out an examination at the intended polyclinic then being examined and given a copy of the prescription by the doctor. Then a payment receipt will also be given and the patient makes a payment transaction at the cashier and gets a receipt and a copy of the prescription as an introduction to get a medicine. The new project development system will cost IDR 41,877,675 in six months. Looks lower because there is a reduction in the cost of using office stationery. However, if it is calculated within one year, it appears that the costs are quite large because there are analysis and design costs, installation costs, and implementation costs. The added values created include: optimizing the quality of service, increasing the efficiency of service time for patients and making reports, reducing the use of paper and office stationery, increasing internal control, and improving decision making.
\end{abstract}

Keywords: accounting information systems, outpatients, inpatients, project development analysis, value-

added

Abstrak

Tujuan penelitian ini adalah untuk menganalisis proses dan prosedur sistem informasi akuntansi pelayanan rawat jalan dan rawat inap Rumah Bersalin dan Klinik Gebang Medika. Selain itu juga untuk menganalisis biaya pengadaan dan cara menciptakan value-added terhadap sistem informasi akuntansi pelayanan pasien rawat jalan dan rawat inap Rumah Bersalin dan Klinik Gebang Medika. Metode pengumpulan data dilakukan dengan pengamatan langsung ke objek penelitian yaitu Rumah Bersalin dan Klinik Gebang Medika. Data yang digunakan adalah data primer. Penelitian ini menggunakan analisis value-added dan perancangannya menggunakan basis teknologi web serta MySQL untuk basis datanya. Hasil dalam penelitian adalah prosedur pelayanan pasien rawat jalan dan rawat inap pada klinik ini dimulai dari pasien datang ke klinik kemudian melakukan pemeriksaan ke poliklinik yang dituju lalu diperiksa dan diberikan salinan resep oleh dokter. Kemudian akan diberikan juga kuitansi pembayaran dan pasien melakukan transaksi pembayaran pada kasir dan mendapatkan kuitansi serta salinan resep sebagai pengantar untuk mendapatkan sebuah obat. Sistem pengembangan proyek yang baru membutuhkan biaya sebesar Rp41.877.675 dalam jangka enam bulan. Terlihat lebih rendah karena terdapat pengurangan biaya pemakaian alat tulis kantor. Walaupun demikian, bila dihitung dalam jangka waktu satu tahun, terlihat biaya yang cukup besar karena terdapat biaya analisis dan desain, biaya instalasi, serta biaya implementasi. Penambahan nilai yang diciptakan antara lain, yaitu: dapat mengoptimalkan kualitas pelayanan, meningkatkan efisiensi waktu pelayanan terhadap pasien dan pembuatan laporan, dapat mengurangi penggunaan kertas dan alat tulis kantor, dapat meningkatkan pengendalian internal, serta meningkatkan pengambilan keputusan.

Kata kunci: sistem informasi akuntansi, pasien rawat jalan, pasien rawat inap, analisis pengembangan proyek, value-added 


\section{PENDAHULUAN}

Dewasa ini kesehatan merupakan salah satu kebutuhan utama masyarakat di Indonesia. Dengan memiliki kesehatan dan kondisi fisik yang baik tentunya akan memudahkan dalam mencari penghasilan, mendapatkan pendidikan yang layak, juga dapat meningkatkan taraf hidup masing-masing individu. Dalam Undang-Undang Nomor 29 Tahun 2004 tentang Praktik Kedokteran dijelaskan bahwa kesehatan sebagai hak asasi manusia harus diwujudkan dalam bentuk pemberian upaya kesehatan kepada seluruh masyarakat melalui penyelenggaraan pelayanan kesehatan yang berkualitas dan terjangkau oleh masyarakat.

Salah satu sarana kesehatan yang berkualitas dan terjangkau oleh masyarakat adalah klinik. Menurut Peraturan Menteri Kesehatan Nomor 028/MENKES/PER/I/2011 pasal 1, klinik adalah fasilitas pelayanan kesehatan yang menyelenggarakan pelayanan kesehatan perorangan yang menyediakan pelayanan medis dasar dan/atau spesialistik, diselenggarakan oleh lebih dari satu jenis tenaga kesehatan dan dipimpin oleh seorang tenaga medis.

Berdasarkan data pada Badan Pusat Statistika tahun 2016, pertumbuhan klinik di Indonesia terutama di daerah Jawa Barat mengalami kondisi yang fluktuatif. Tahun 2008 terdapat 1.449 klinik dan tahun 2011 mengalami penurunan menjadi 1.355 klinik. Sedangkan tahun 2014 mengalami kenaikan sebesar $11 \%$. Peningkatan jumlah klinik ini tentunya harus disertai dengan peningkatan pelayanan sehingga klinik yang ada semakin prima dalam melayani masyarakat Salah satu hal yang dilakukan adalah bekerja sama dengan BPJS dan menggunakan sistem yang terintegrasi dengan baik.

Badan Penyelenggara Jaminan Sosial (BPJS) Kesehatan adalah badan hukum yang dibentuk untuk menyelenggarakan program jaminan kesehatan. BPJS Kesehatan ini sudah mulai beroperasi pada 1 Januari 2014 dan semua penduduk Indonesia wajib menjadi peserta BPJS termasuk orang asing yang telah bekerja paling singkat enam bulan di Indonesia dan telah membayar iuran (Kemenkes, 2013). Salah satu klinik yang sudah melakukan kerja sama dengan BPJS Kesehatan adalah Rumah Bersalin dan Klinik Gebang Medika. Klinik tersebut telah melakukan kerja sama dengan BPJS Kesehatan mulai awal tahun 2014 dan setelah itu pengunjung (pasien) klinik ini mengalami peningkatan yang cukup signifikan.Data ini dapat dilihat pada tabel 1.

Tabel 1.

Jumlah Pengunjung (Pasien) Klinik Gebang Medika Tahun 2013-2015

\begin{tabular}{ccccc}
\hline No & Bulan & Tahun 2013 & Tahun 2014 & Tahun 2015 \\
\hline $\mathbf{1}$ & Januari & 1489 & 930 & 2276 \\
$\mathbf{2}$ & Februari & 1429 & 974 & 2616 \\
$\mathbf{3}$ & Maret & 1306 & 1143 & 2886 \\
$\mathbf{4}$ & April & 1074 & 1282 & 2843 \\
$\mathbf{5}$ & Mei & 1249 & 1133 & 2826 \\
$\mathbf{6}$ & Juni & 1263 & 1200 & 2816 \\
$\mathbf{7}$ & Juli & 1110 & 1024 & 2788 \\
$\mathbf{8}$ & Agustus & 1058 & 1569 & 3482 \\
$\mathbf{9}$ & September & 1233 & 1541 & 3501 \\
$\mathbf{1 0}$ & Oktober & 1147 & 1626 & 3847 \\
$\mathbf{1 1}$ & November & 1004 & 1848 & 3866 \\
$\mathbf{1 2}$ & Desember & 966 & 2037 & 3699 \\
& TOTAL & $\mathbf{1 4 . 3 2 8}$ & $\mathbf{1 6 . 3 0 7}$ & $\mathbf{3 7 . 4 4 6}$ \\
\hline
\end{tabular}


Peningkatan jumlah pengunjung (pasien) klinik ini tidak dibarengi dengan kemajuan sistem yang digunakan. Sistem yang digunakan oleh Klinik Gebang Medika masih bersifat manual. Sistem informasi merupakan cara untuk menghasilkan informasi yang berguna, cepat, akurat, dan tepat waktu. Informasi yang berguna akan mendukung sebuah pengambilan keputusan bagi pemakainya dan melakukan tindakan secara tepat berdasarkan informasi yang dihasilkan tersebut (Noor, 2011).

Salah satu sistem informasi yang dibutuhkan adalah sistem informasi akuntansi pelayanan pasien rawat jalan dan rawat inap. Unit rawat inap dan rawat jalan ini merupakan unit yang setiap harinya melakukan aktivitas pelayanan terhadap pasien. Pasien yang diterima di klinik akan mendapatkan pelayanan pengobatan dan diberikan diagnosa oleh dokter selanjutnya dapat dirujuk, kontrol ulang, dirawat atau mendapat rujukan untuk dilakukan pemeriksaan penunjang medis di antaranya laboratorium, rontgen maupun rehabilitasi medik.

Dengan adanya sistem informasi akuntansi terhadap pelayanan pasien di klinik ini diharapkan dapat memberikan pelayanan yang prima kepada masyarakat dan memaksimalkan kinerja semua pegawai klinik. Sistem informasi akuntansi juga dapat menambah nilai (valueadded) terhadap sebuah organisasi termasuk pada klinik ini dengan cara mengoptimalkan kualitas pelayanan, meningkatkan efisiensi waktu pelayanan terhadap pasien, dan meningkatkan pengambilan keputusan. Sehingga dengan adanya sistem ini diharapkan informasi dan hasil pemeriksaan yang diberikan akurat, waktu pelayanan terhadap pasien lebih cepat, serta pengambilan keputusan jangka panjang dapat dilakukan secara lebih tepat dan terencana dengan baik.

Di sisi lain, peningkatan kinerja dan pelayanan kepada masyarakat seperti yang telah digambarkan di atas dan disertai dengan usulan penggunaan sistem yang lebih terkomputerisasi akan membuat masyarakat menjadi lebih percaya terhadap pelayanan klinik sehingga menjadi pelanggan tetap klinik ini. Hal ini akan membuat laba klinik menjadi lebih meningkat. Peningkatan laba klinik tentunya akan membuat klinik lebih mengabdikan diri terhadap masyarakat sekitar dengan memberikan kontribusinya seperti menyediakan sunat massal dan pengobatan secara gratis.

Berdasarkan uraian di atas, tujuan dari penelitian ini adalah menganalisis proses dan prosedur sistem informasi akuntansi pelayanan rawat jalan dan rawat inap Rumah Bersalin dan Klinik Gebang Medika. Selain itu juga untuk menganalisis biaya pengadaan dan cara menciptkan value-added terhadap sistem informasi akuntansi pelayanan pasien rawat jalan dan rawat inap Rumah Bersalin dan Klinik Gebang Medika.

\section{Sistem Informasi Akuntansi}

Menurut Romney dan Steinbart (2014 : 28), sistem informasi akuntansi adalah sistem yang mengumpulkan, mencatat, menyimpan, dan memproses data sehingga menghasilkan informasi untuk sebuah keputusan. Sistem informasi akuntansi adalah kumpulan sumber daya seperti orang dan perlengkapan, yang dirancang untuk mengubah data keuangan dan data lainnya menjadi informasi (Bodnar, 2006)

\section{Rawat Jalan}

Menurut Keputusan Menteri Kesehatan RI Nomor 560/MENKES/SK/IV/2003 tentang tarif rumah sakit bahwa pasien rawat jalan adalah pelayanan pasien rawat jalan adalah pelayanan 
pasien untuk observasi, diagnosis, pengobatan rehabilitasi, medis, dan pelayanan kesehatan lainnya tanpa menginap.

\section{Rawat Inap}

Rawat inap tingkat lanjutan menurut Menteri Kesehatan RI Nomor 138/MENKES//PB/II/2009 adalah pelayanan kesehatan perorangan yang bersifat spesialistik atau sub-spesialistik untuk keperluan observasi, perawatan, diagnosis, pengobatan, rehabilitasi medis dan/atau pelayanan medis lainnya termasuk konsultasi psikologi, yang dilaksanakan pada PPK (Pemberi Pelayanan Kesehatan) tingkat lanjutan di mana peserta atau anggota keluarganya dirawat inap di ruang perawatan paling singkat satu hari.

\section{Nilai Tambah (Value-Added)}

Menurut Romney dan Steinbart (2014:11), sistem informasi akuntansi yang didesain dengan baik dapat menambah nilai untuk sebuah organisasi yaitu dengan cara :

1. Meningkatkan kualitas dan mengurangi biaya produk atau jasa;

2. Meningkatkan efisiensi;

3. Berbagi pengetahuan;

4. Meningkatkan struktur pengendalian internal;

5. Meningkatkan pengambilan keputusan;

Value-added adalah aktivitas yang dalam prespektif konsumen memberikan nilai tambah pada produk atau jasa. Termasuk di dalamnya adalah memproses material menjadi produk setengah jadi atau produk jadi (Tebiary, 2017).

\section{METODE}

Data primer yang digunakan adalah data jumlah pengunjung (pasien), data jumlah pegawai, juga proses dan prosedur yang sudah diterapkan pada Rumah Bersalin dan Klinik Gebang Medika. Sedangkan data sekunder yang digunakan adalah struktur organisasi, kartu berobat, daftar hadir pasien umum dan BPJS, kartu rekam medis (KRM), salinan resep, surat kontrol pasien, surat keterangan sakit, kuitansi pembayaran, serta laporan keuangan.

Metode pengumpulan data dalam penelitian ini ialah observasi, wawancara, dan analisis data. Sedangkan metode pengembangan sistem melalui beberapa tahap, yaitu (1) tahap perencanaan sistem, (2) tahap analisis sistem, (3) tahap perancangan sistem, (4) tahap implementasi sistem, serta (5) tahap pengujian dan penggunaan sistem. 


\section{HASIL DAN PEMBAHASAN}

\section{Data Flow Diagram}

\section{Diagram Context}

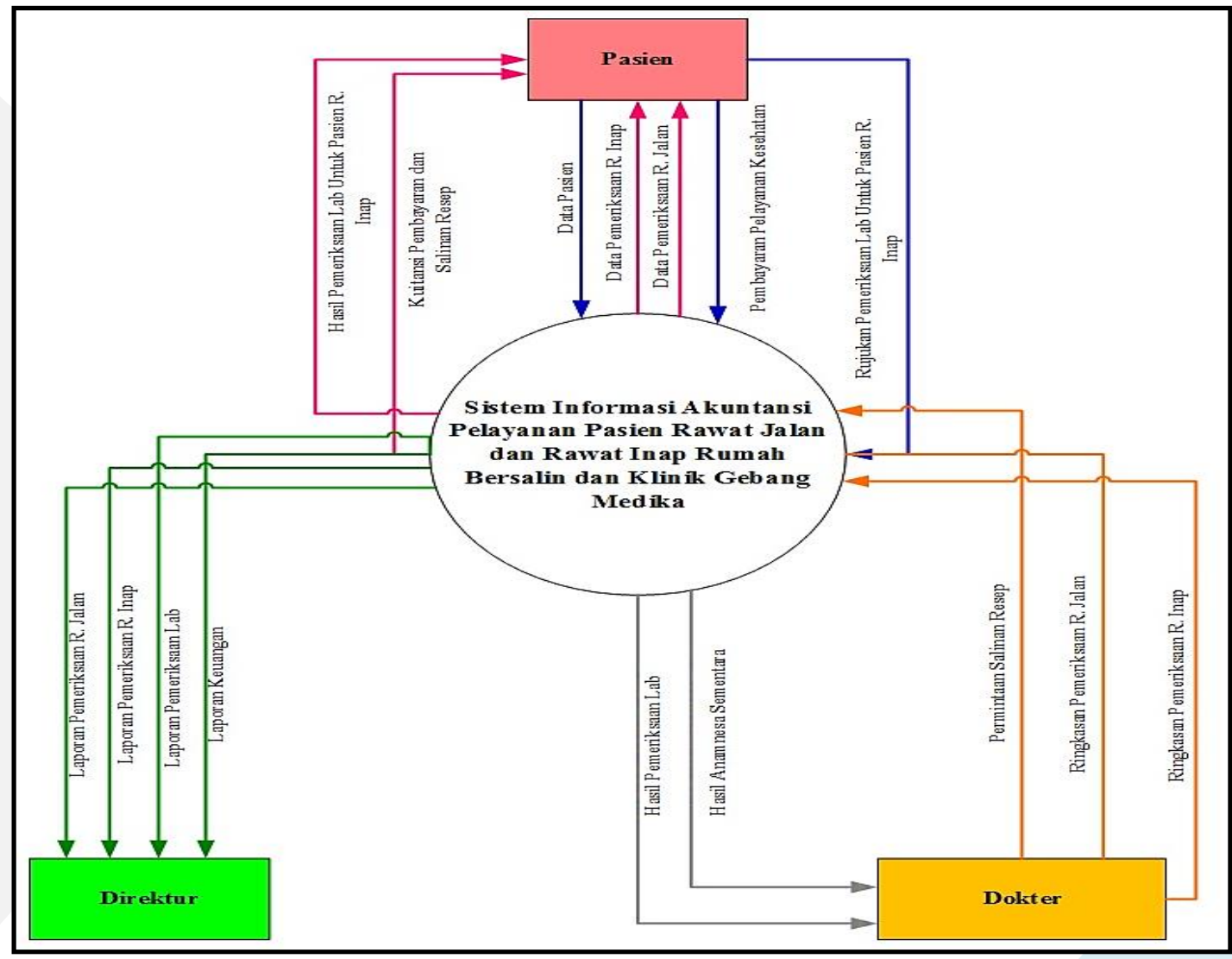

Sumber : Data Diolah, (2016)

Gambar 1. Diagram Context Sistem Informasi Akuntansi Pelayanan Pasien Rawat Jalan dan Rawat Inap Rumah Bersalin dan Klinik Gebang Medika

Diagram context merupakan level tertinggi dari Data Flow Diagram (DFD) yang menggambarkan seluruh input ke sistem atau output dari sistem. Dari diagram context di atas menunjukkan bahwa sistem informasi akuntansi pelayanan pasien rawat jalan dan rawat inap diawali dengan pasien yang mendaftarkan diri ke klinik dengan memberikan informasi tentang data diri secara detail kemudian data pasien tersebut diolah oleh sistem dan menghasilkan data pemeriksaan rawat jalan dan inap. Setelah proses pendaftaran selesai, pasien melakukan test tanda-tanda vital dan ditanya keluhan penyakitnya oleh perawat. Hasil anamnesis sementara diberikan oleh sistem ke dokter yang memeriksa. Setelah pemeriksaan selesai dan dokter masih belum dapat menetapkan diagnosis terhadap pasien maka pasien akan mendapat rujukan pemeriksaan laboratorium dan sistem akan mengeluarkan hasil laboratorium tersebut melalui bagian laboratorium. Laporan tersebut akan dilaporkan dan diperiksa oleh direktur tiap akhir bulan. Sistem juga akan mengeluarkan hasil laboratorium tersebut untuk dokter agar bisa mendiagnosis penyakit pasien serta dapat membuat dan meng-input ringkasan pemeriksaan rawat jalan dan inap. Dokter juga meng-input permintaan salinan resep ke sistem yang nantinya akan diberikan ke pasien setelah pasien melakukan pembayaran pelayanan kesehatan. Pasien akan 
mendapatkan kuitansi pembayaran dan salinan resep sebagai output-nya. Pada akhir bulan sistem akan mengeluarkan laporan rawat jalan dan inap yang dibuat oleh dokter dan laporan keuangan serta laporan tersebut diserahkan kepada direktur untuk diperiksa.

\section{Diagram Context}

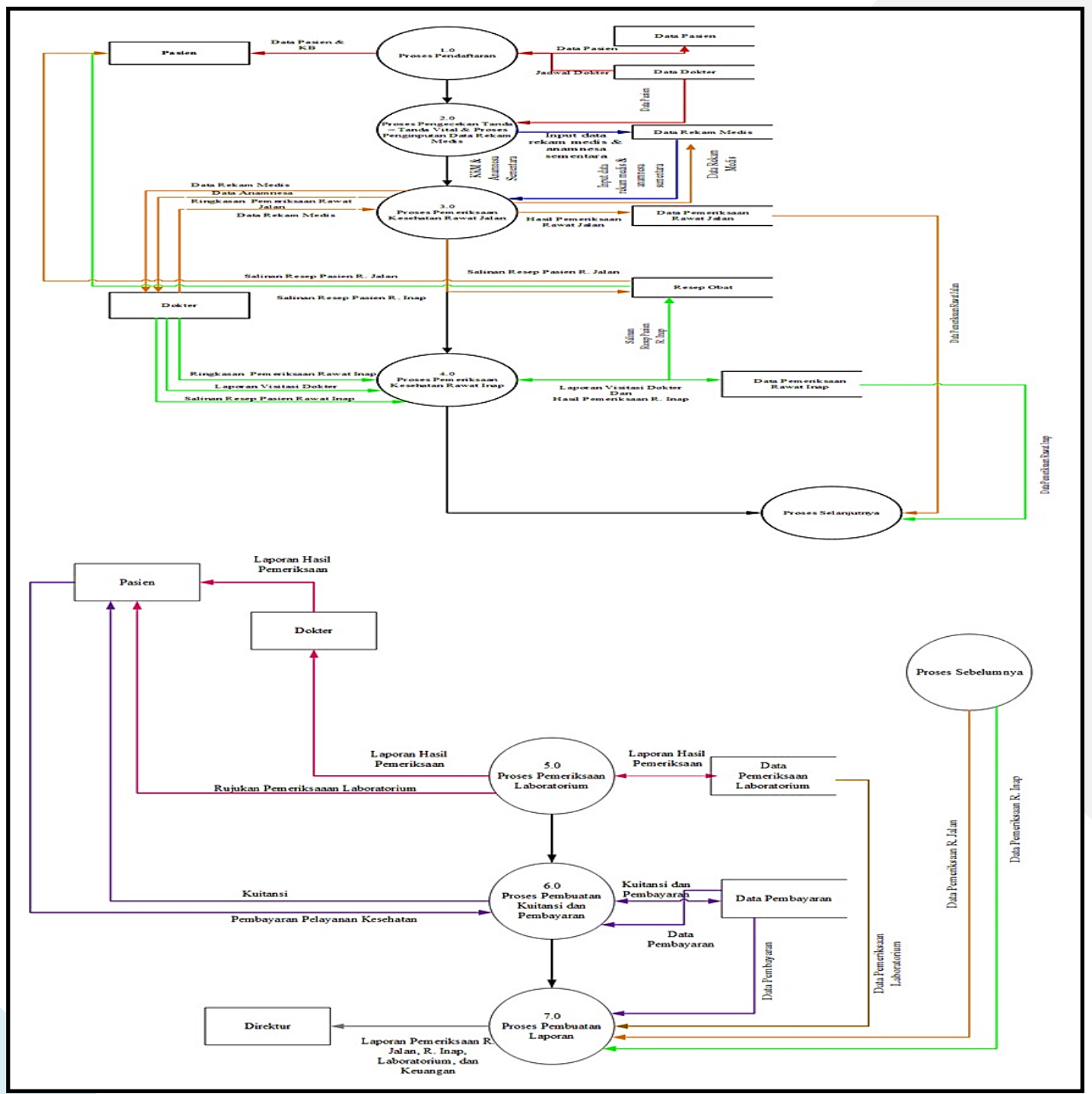

Sumber: Data Diolah, (2016)

Gambar 2. Diagram Zero Sistem Informasi Akuntansi Pelayanan Pasien Rawat Jalan dan Rawat Inap Rumah Bersalin dan Klinik Gebang Medika

Diagram zero adalah diagram yang menggambarkan seluruh proses yang terjadi di diagram context. Pada sistem pelayanan rawat jalan dan inap pada Klinik Gebang Medika ini terdapat tujuh proses. Gambar diagram zero dapat dilihat pada gambar 2.

Proses pertama adalah proses pendaftaran. Pada proses ini, pasien memberikan data pasien ke bagian pendaftaran. Bagian pendaftaran menginput data tersebut ke dalam sistem. Sistem akan mengeluarkan output berupa data pasien yang akan melakukan pemeriksaan pada klinik ini dan kartu berobat yang akan diserahkan kembali ke pasien. Setelah pasien melakukan 
pendaftaran, pasien akan mendapatkan jadwal dokter untuk mengetahui siapa sajakah dokter yang bertugas. Data input pasien ini akan disimpan pada database data pasien dan database data dokter akan mengeluarkan jadwal dokter.

Proses kedua adalah proses pengecekan tanda-tanda vital dan proses penginputan data rekam medis. Proses ini membutuhkan input data pasien yang diperoleh dari proses sebelumnya. Proses ini menghasilkan output yaitu input rekam medis dan anamnesis sementara. Proses anamnesis dilakukan perawat untuk mengetahui keluhan yang diderita pasien. Sementara input rekam medis dilakukan oleh bagian rekam medis. Penginputan rekam medis ini dilakukan agar dokter atau bidan yang memeriksa tahu akan riwayat pasien. Output ini disimpan pada database data rekam medis dan akan selalu update bila terjadi perubahan. Data rekam medis dan anamnesis sementara akan dibawa ke proses selanjutnya.

Proses ketiga adalah proses pemeriksaan kesehatan rawat jalan. Proses ini membutuhkan input yaitu data rekam medis dan anamnesis sementara yang diperoleh dari proses sebelumnya. Input ini di proses dan menghasilkan data rekam medis dan data anamnesis selanjutnya diberikan kepada dokter. Kemudian dokter melakukan pemeriksaan kepada pasien setelah itu membuat ringkasan pemeriksaan rawat jalan serta melakukan update data rekam medis. Proses terakhir yang dilakukan dokter adalah membuat salinan resep untuk pasien agar dapat digunakan untuk membeli obat di apotek terdekat. Ringkasan pemeriksaan rawat jalan, data rekam medis, dan salinan resep diproses oleh sistem dan output nya di simpan pada database yang berbeda. Hasil pemeriksaan disimpan pada database pemeriksaan rawat jalan, data rekam medis disimpan pada database rekam medis, dan salinan resep disimpan pada database resep obat. Salinan resep pasien rawat jalan itu akan diberikan kepada pasien setelah selesai melakukan pembayaran.

Proses keempat adalah proses pemeriksaan kesehatan rawat inap. Proses ini membutuhkan input yaitu hasil pemeriksaan rawat jalan yang diperoleh dari proses ketiga. Input ini diproses pada sistem. Selanjutnya dokter melakukan pemeriksaan terhadap pasien dan membuat ringkasan pemeriksaan rawat inap. Dokter juga membuat laporan visitasi di mana visitasi itu dilakukan sebanyak satu kali dalam sehari. Terakhir dokter membuat salinan resep untuk pasien yang sudah diperbolehkan untuk pulang. Selain itu, dokter juga membuat surat rujukan pemeriksaan laboratorium dan diserahkan kepada pasien jika penyakit yang diderita pasien cukup serius dan membutuhkan hasil laboratorium untuk membantu melakukan diagnosis terhadap pasien. Surat rujukan itu kemudian diserahkan kepada petugas laboratorium. Output dari proses keempat adalah hasil pemeriksaan rawat inap, laporan visitasi dokter, dan salinan resep. Hasil pemeriksaan rawat inap dan laporan visitasi dokter disimpan pada database data pemeriksaan rawat inap. Sedangkan salinan resep disimpan pada database resep obat. Salinan resep itu juga diberikan kepada pasien rawat inap jika pasien telah selesai melakukan pembayaran.

Proses kelima adalah proses pemeriksaan laboratorium. Surat rujukan yang dibawa oleh pasien diserahkan kepada petugas laboratorium. Petugas laboratorium lalu melakukan pemeriksaan (cek) darah kepada pasien. Setelah hasil pemeriksaan keluar, kemudian diberikan kepada dokter agar dapat melakukan diagnosis terhadap pasien. Setelah itu dokter menyerahkan kembali ke pasien saat akan pulang. Petugas laboratorium kemudian membuat laporan hasil pemeriksaan dan datanya disimpan dalam database pemeriksaan laboratorium.

Proses keenam adalah proses pembuatan kuitansi dan pembayaran. Kasir membuat dua rangkap kuitansi pembayaran. Satu rangkap untuk pasien dan satu rangkap lainnya untuk disimpan pada database. Kuitansi rangkap satu diserahkan kepada pasien dan pasien melakukan

Analysis of Development Costs and ValueAdded Accounting Information Systems on Road and Inpatient Services at Cribs and Gebang Medika Clinic 
pembayaran. Uang dan kuitansi yang diterima oleh kasir kemudian diberikan kepada bagian keuangan. Sedangkan kuitansi disatukan oleh kasir dan di input ke dalam sistem dan menghasilkan data pembayaran. Jika telah selesai kuitansi dan data pembayaran disimpan pada database data pembayaran.

Proses ketujuh atau yang terakhir adalah proses pembuatan laporan. Proses ini dilakukan oleh bagian akuntansi. Proses ini membutuhkan input data pemeriksaan rawat jalan, data pemeriksaan rawat inap, pemeriksaan laboratorium dan data pembayaran. Semua data tersebut diolah sistem dan menghasilkan output berupa laporan rawat jalan, laporan rawat inap, pemeriksaan lab, dan laporan keuangan. Semua laporan itu diserahkan kepada direktur untuk diperiksa dan disetujui.

\section{Implementasi Sistem}

Implementasi aplikasi sistem ini dibangun dengan menggunakan bahasa pemrograman yaitu Hypertext Preprocessor (PHP) dengan MySQL sebagai databasenya. Adapun implementasi sistemnya adalah sebagai berikut:

1. Tampilan Pendaftaran Rawat Jalan

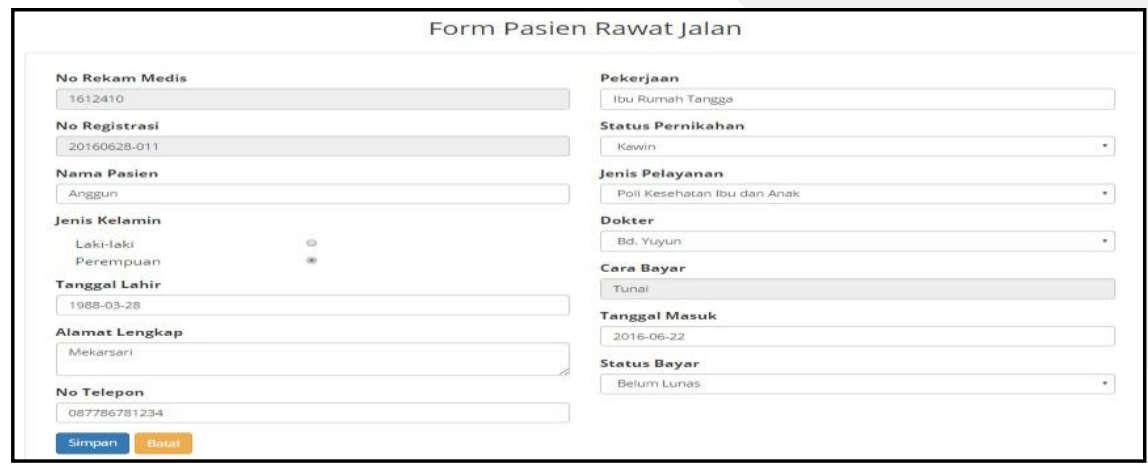

Sumber: Data Diolah, (2016)

Gambar 3. Tampilan Input Pendaftaran Rawat Jalan

2. Tampilan Pendaftaran Rawat Inap

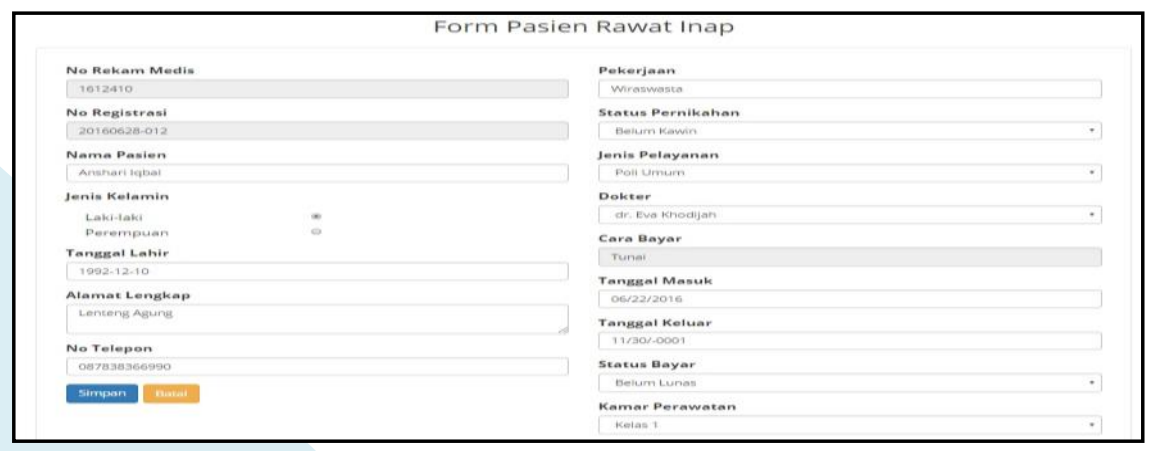

Sumber: Data Diolah, (2016)

Gambar 4. Tampilan Input Pendaftaran Rawat Inap

3. Data Pemeriksaan Rawat Jalan dan Rawat Inap 


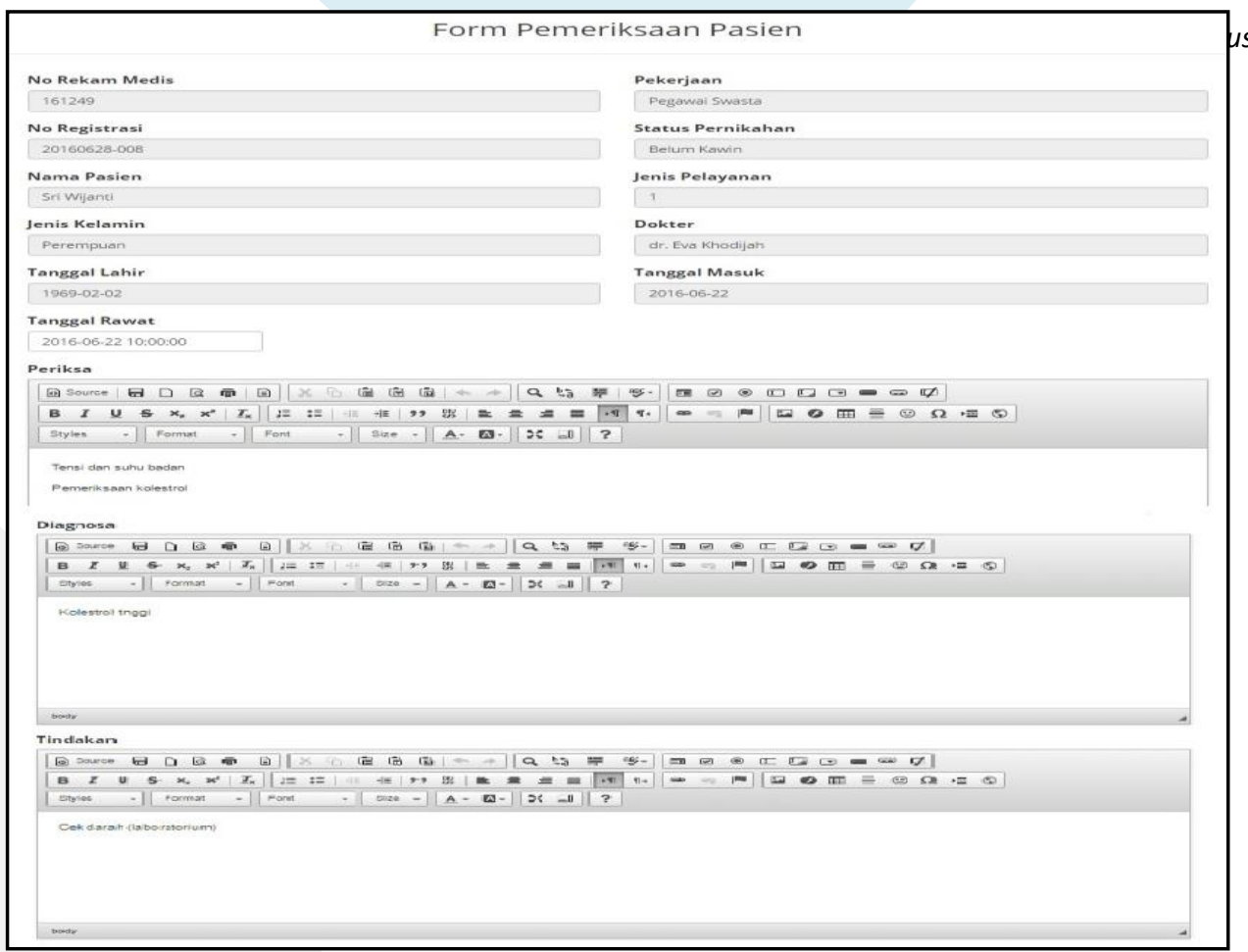

Sumber: Data Diolah, (2016)

Gambar 5. Tampilan Data Pasien Rawat Jalan dan Rawat Inap

\section{Kartu Rekam Medis}

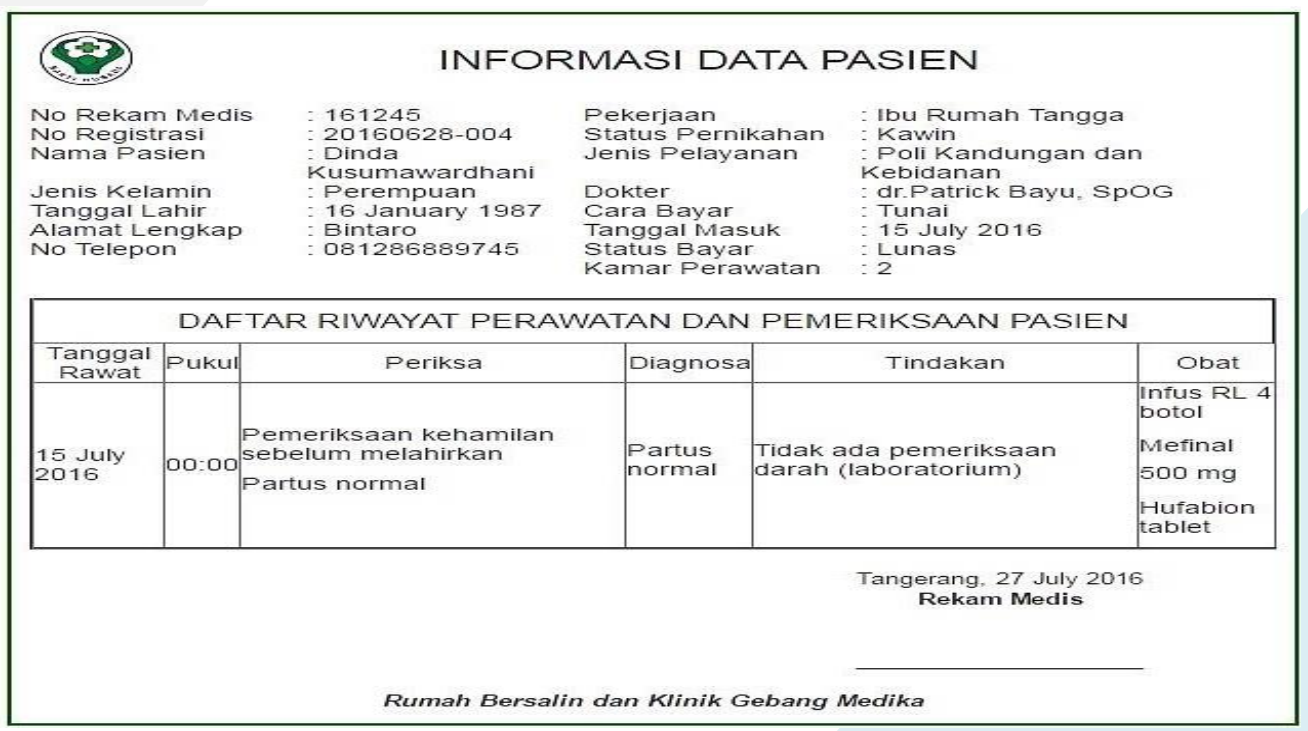

Sumber: Data Diolah, (2016)

Gambar 6. Kartu Rekam Medis

5. Input Kuitansi Rawat Jalan

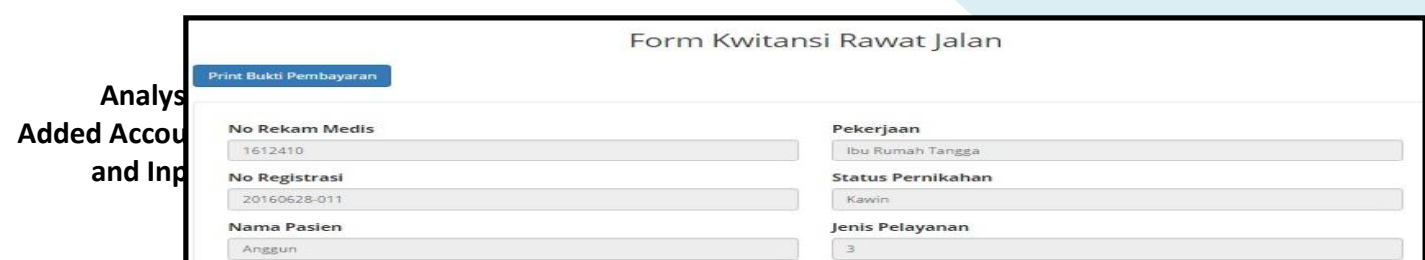


6. Input Kuitansi Rawat Inap

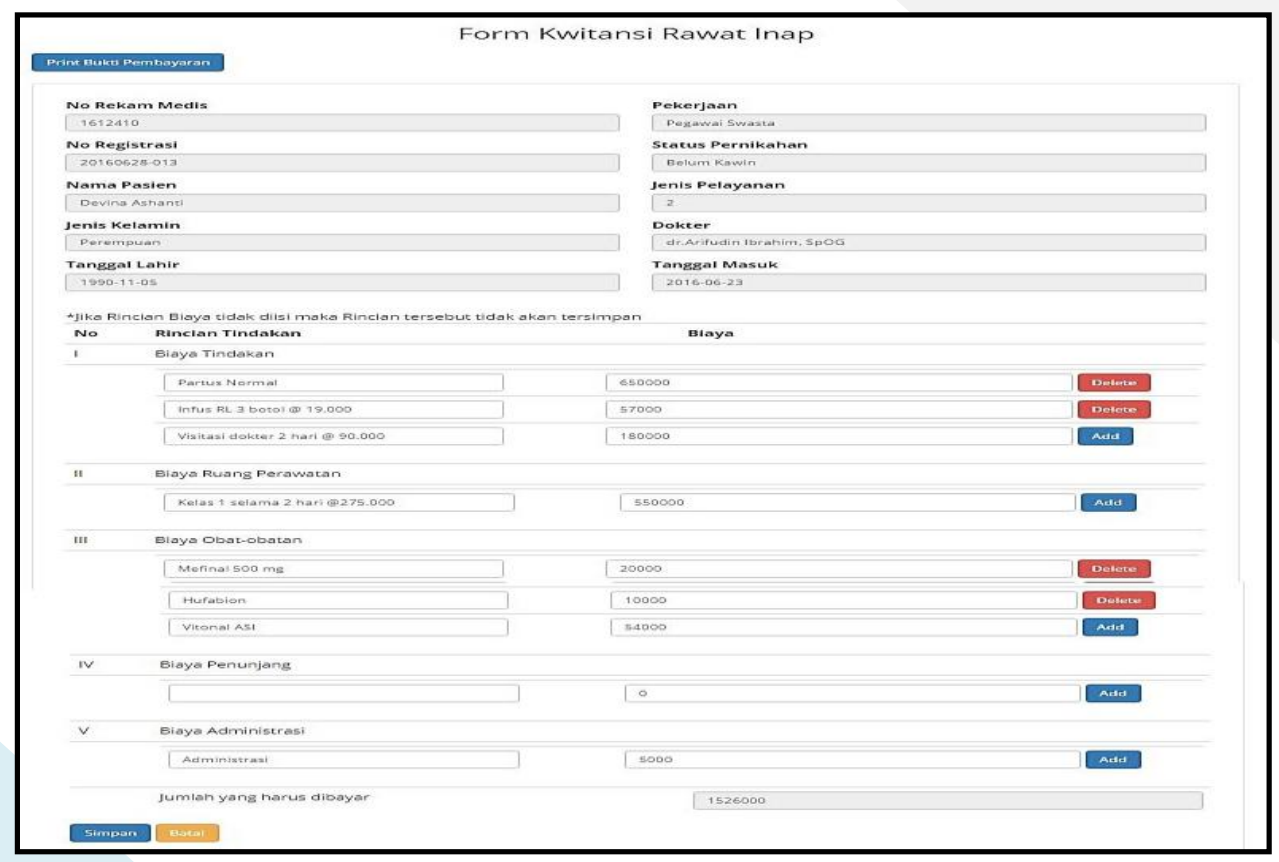

Sumber: Data Diolah, (2016)

Gambar 8. Input Kuitansi Rawat Inap

7. Output Kuitansi Rawat Jalan

\section{BUKTI PEMBAYARAN PASIEN RAWAT JALAN}

No Rekam Medis

:20160628-011

Nama Pasien

Jenis Kelamin

Tanggal Lahir

Alamat Lengkap

Anggun

Perempuan

28 March 1988

Mekarsari

087786781234

Pekerjaan

Status Pernikaha

Jenis Pelayanan

Dokter

Cara Bayar

Tanggal Masu

Status Bayar

Ibu Rumah Tangga

Kawin

oli Kesehatan Ibu dan Anak

Bd. Yuyun

Tunai

17 July 2016 Lunas 
8. Output Kuitansi Rawat Inap

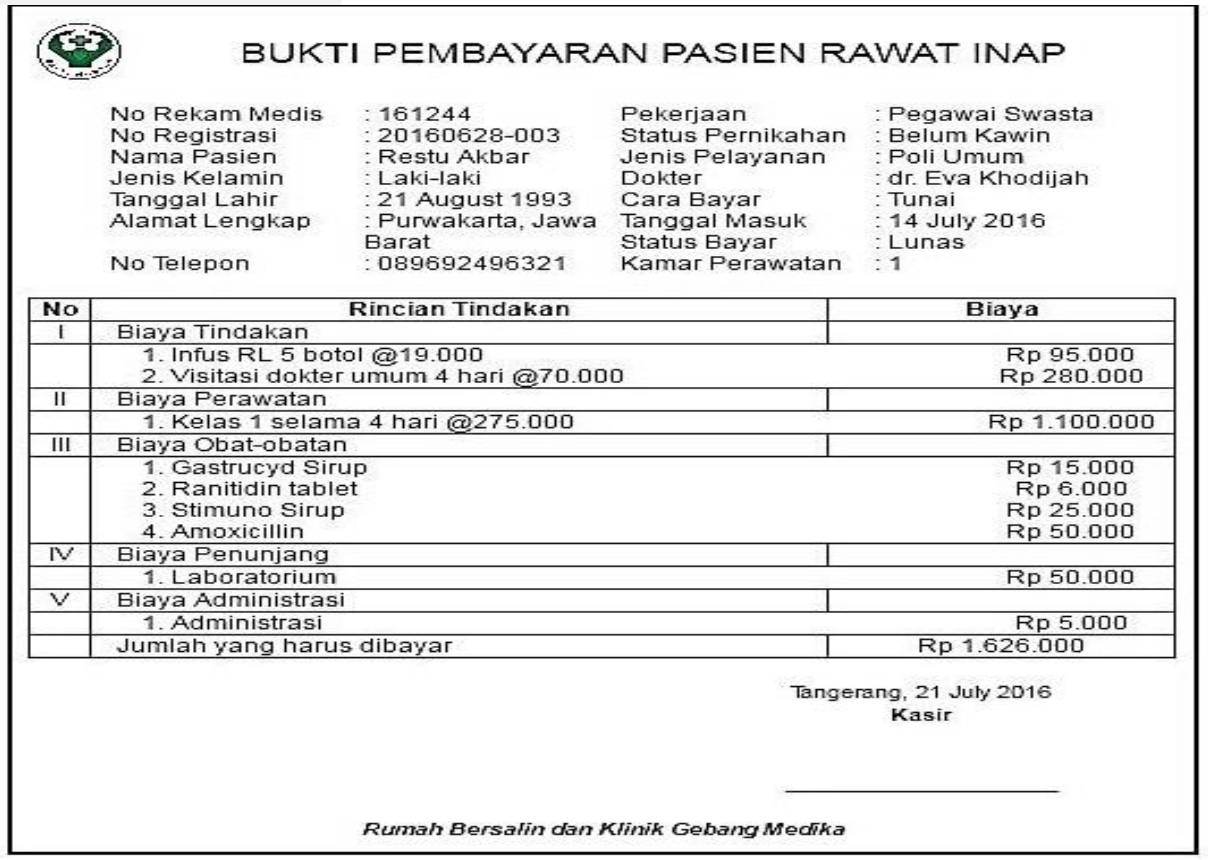

Sumber: Data Diolah, (2016)

Gambar 10. Output Kuitansi Rawat Inap

9. Slip Gaji Pegawai

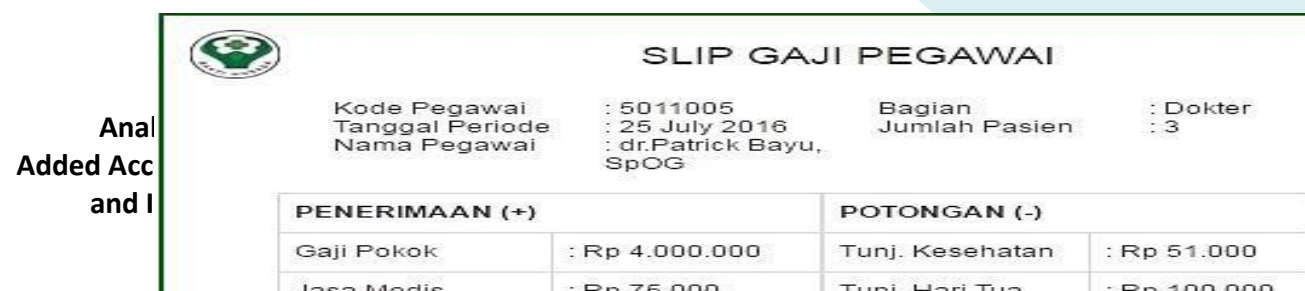


10. Jurnal Umum

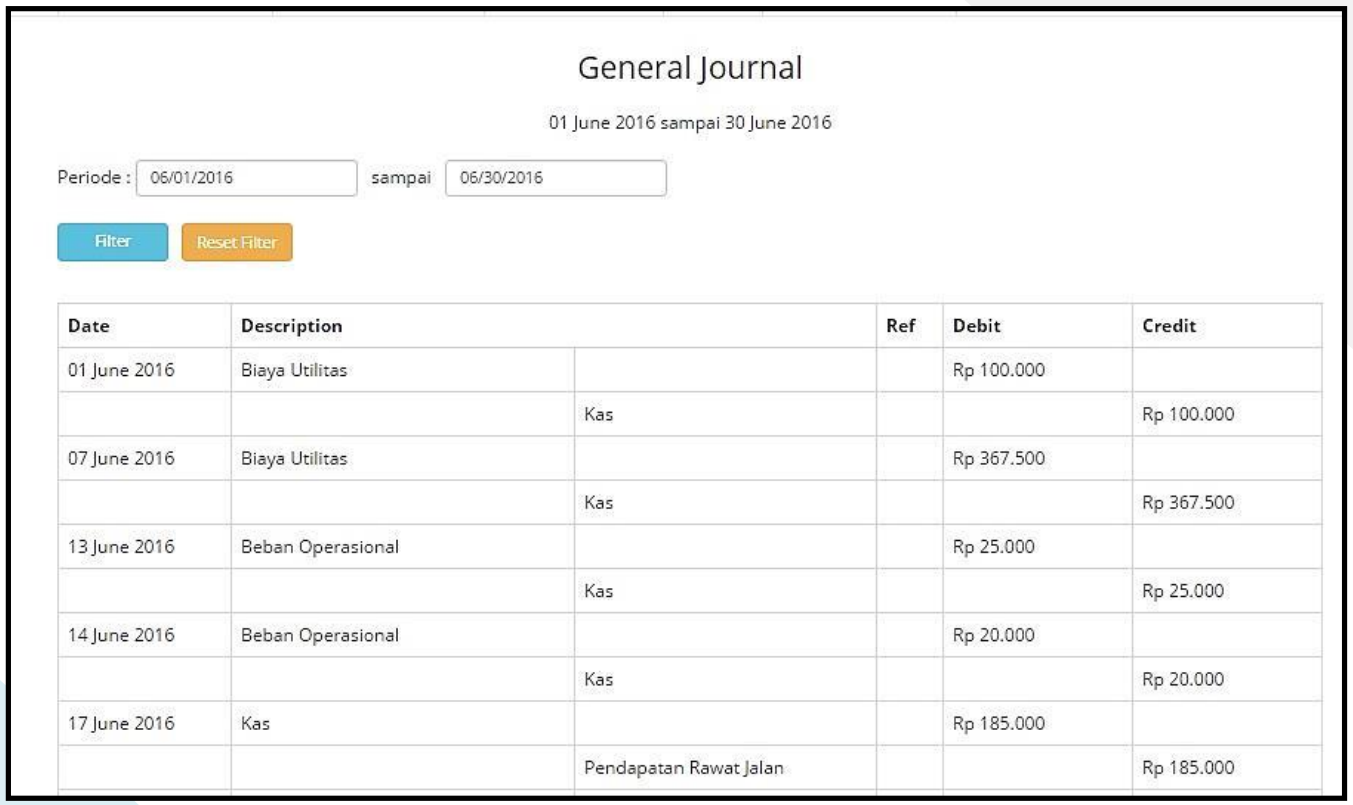

Sumber : Data Diolah, (2016)

Gambar 12. Jurnal Umum

11. Laporan Posisi Keuangan

\begin{tabular}{l|l|l|l|l|l} 
Kwintansi Rawatjalan & Kwintansi Rawat Inap & Slip Gaji Pegawai Jurnal & Laporan Keuangan
\end{tabular}


Analisis Biaya Pengembangan Proyek Sistem Informasi Akuntansi Pelayanan Pasien Rawat Jalan dan Rawat Inap pada Rumah Bersalin dan Klinik Gebang Medika

Biaya pengembangan proyek terdiri dari dua yaitu analisis sistem lama dan analisis sitem yang baru. Perbedaan biaya yang terjadi antara sistem lama dan sistem baru disebabkan oleh penyusunan dan pemasangan aplikasi baru yang membutuhkan seorang programmer andal. Desain aplikasi sistem yang baru di buat dengan rencana yang matang sehingga membutuhkan biaya perencanaan yang jumlahnya sebesar Rp1.995.000,- (Tabel 3). Jumlah yang cukup signifikan ini sangat berpengaruh pada aplikasi yang disusun. Semakin baik perencanaannya tentunya aplikasi yang dibuat akan semakin baik hasilnya.

Terlihat perbedaan jumlah biaya antara sistem lama dan baru yang cukup signifikan. Pada sistem lama jumlah yang dikeluarkan dalam jangka waktu setahun adalah Rp 82.195.200,- dan sistem baru dalam jangka waktu enam bulan (siklus satu tahun) adalah Rp 41.877.675,-. Biaya yang dihasilkan pada sistem baru terlihat lebih rendah daripada sistem lama karena terdapat pengurangan pemakaian alat tulis kantor seperti kertas, pulpen, buku folio, tukang service komputer, dan install ulang komputer. Walaupun demikian, bila dihitung dalam jangka waktu satu tahun terlihat cukup besar biaya pada sistem baru. Hal itu dikarenakan pada tahun pertama sistem baru terdapat biaya analisis dan desain, biaya installasi, biaya implementasi, dan biaya lain-lain yang besar nilainya. Adapun analisis biaya pengembangan proyek adalah sebagai berikut:

Tabel 2.

Analisis Biaya Pengembangan Proyek Sistem Lama

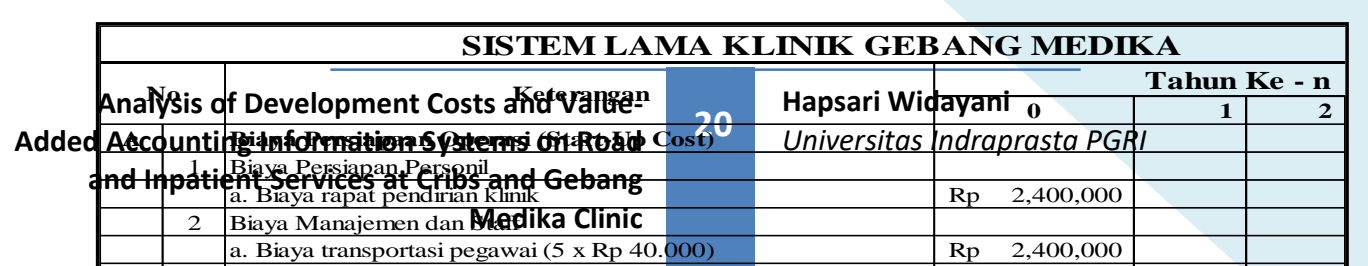


Analysis of Development Costs and Value-Added Accounting Information Systems on Road and Inpatient Services at Cribs and Gebang Medika Clinic

Hapsari Widayan

https://doi.org/10.37010/nuc.v1i1.78

Tabel 3.

Analisis Biaya Pengembangan Proyek Sistem Baru

\begin{tabular}{|c|c|c|c|c|c|c|}
\hline \multicolumn{7}{|c|}{ SISTEMI BARU KIINT } \\
\hline \multicolumn{3}{|c|}{ No } & \multirow{2}{*}{ KETERANGAN } & \multirow[t]{2}{*}{ o } & \multirow{2}{*}{1} & \multirow{2}{*}{2} \\
\hline $\mathbf{A}$ & & BIA & & & & \\
\hline & $\mathbf{I}$ & BLA & YAKONSULTAN & & & \\
\hline & & 1 & Manajer Proyek (66 hari x Rp $100.000 @ 1$ orang) & $6,600,000$ & & \\
\hline & & 2 & Programmer (90 hari x Rp $150.000 @ 1$ orang) & $13,500,000$ & & \\
\hline & & & Desainer (90 hari x Rp $150.000 @ 1$ orang) & $13,500,000$ & & \\
\hline & & & $\begin{array}{l}\text { TOTAL BLAYA KONSULTAN } \\
\end{array}$ & $33,600,000$ & & \\
\hline & II & TAB & AP PERENCANAAN & & & \\
\hline
\end{tabular}


Cara Menciptakan Value-added terhadap Sistem Informasi Akuntansi Pelayanan Pasien Rawat Jalan dan Rawat Inap pada Rumah Bersalin dan Klinik Gebang Medika

Penambahan nilai (value-added) pada sistem informasi akuntansi pelayanan rawat jalan dan rawat inap pada Rumah Bersalin dan Klinik Gebang Medika adalah sebagai berikut:

1. Dapat mengoptimalkan kualitas pelayanan

Analysis of Development Costs and ValueAdded Accounting Information Systems on Road and Inpatient Services at Cribs and Gebang 
Hasil yang diberikan adalah informasi dan hasil pemeriksaan sangat akurat dan mudah di dapat.Informasi ini berupa softcopy yang dapat dicetak.

2. Meningkatkan efisiensi waktu pelayanan terhadap pasien dan pembuatan laporan

Pelayanan pasien pada saat mendaftar di sistem baru diharapkan dapat selesai dalam waktu kurang lebih 5 menit karena sudah menggunakan sistem database yang terstruktur dengan baik sedangkan pada sistem lama membutuhkan waktu sekitar 15 menit.

Pembuatan laporan dengan menggunakan sistem baru membutuhkan waktu sekitar dua jam berbeda dengan sistem yang lama yaitu membutuhkan waktu satu minggu untuk membuat sebuah laporan. Dari penjelasan tersebut terlihat bahwa waktu yang digunakan pada sistem baru lebih efisien daripada sistem lama.

\section{Dapat mengurangi penggunaan kertas dan alat tulis kantor (ATK)}

Penggunaan kertas dan ATK yang banyak dapat membutuhkan biaya yang besar dalam sebuah pengeluaran yang rutin. Dampaknya pendapatan klinik menjadi berkurang dan membuat performa menjadi kurang baik. Hal ini dapat diminimalisir dengan menggunakan sebuah aplikasi seperti yang telah penulis rancang. Pada sistem baru untuk membuat laporan hanya membutuhkan kertas hvs dan tinta print saja berbeda dengan sistem lama yang membutuhkan buku folio besar, alat tulis kantor, kuitansi penerimaan dan pengeluaran, dan alat hitung (kalkulator) sehingga membuat biaya operasional menjadi tinggi.

Dengan adanya sistem yang baru dapat menekan biaya operasional klinik sehingga pendapatan klinik menjadi bertambah dan lebih efektif penggunaan kertas serta ATK. Di sisi lain, pengurangan biaya yang ditimbulkan dari selisih sistem yang lama dan sistem yang baru dapat dialokasikan penggunaannya untuk penambahan aset klinik dan membantu masyarakat sekitar dengan memberikan pengobatan yang jauh lebih layak dengan harga yang sangat memadai.

\section{Dapat meningkatkan pengendalian internal}

Pada sistem yang baru, sistem dirancang agar dapat diakses oleh semua bagian sesuai dengan tugas dan tanggung jawab masing-masing sehingga setiap bagian yang memiliki otorisasi bisa masuk ke dalam sistem. Penyimpanan dokumen pada sistem lama masih manual dan disimpan dalam bentuk arsip-arsip. Berbeda dengan sistem baru, di mana penyimpanan dokumen sudah menerapkan sistem database yang baik sehingga bila diperlukan dapat dicari dengan lebih mudah dan terstruktur dengan baik.

5. Meningkatkan pengambilan keputusan

Informasi yang dihasilkan dari sistem yang baru sangat mudah diakses dan akurat sehingga manajemen klinik dapat menggunakan informasi tersebut untuk pengambilan keputusan jangka panjang.

\section{PENUTUP}

Prosedur pelayanan pasien rawat jalan dan rawat inap pada klinik ini dimulai dari pasien datang ke klinik kemudian melakukan pemeriksaan ke poliklinik yang dituju lalu diperiksa dan diberikan salinan resep oleh dokter. Kemudian akan diberikan juga kuitansi pembayaran dan 
pasien melakukan transaksi pembayaran pada kasir dan mendapatkan kuitansi serta salinan resep sebagai pengantar untuk mendapatkan sebuah obat. Bagian-bagian yang terkait adalah direktur, kepala instalasi rawat jalan, kepala instalasi rawat inap, kepala instalasi farmasi, instalasi laboratorium, kepala HRD dan umum, kepala humas, dokter, bidan, administrasi, rekam medis, perawat, kasir, akuntansi, keuangan, serta pendaftaran. Dokumen yang digunakan adalah kartu berobat, kartu rekam medis, kuitansi, salinan resep, laporan visitasi, buku riwayat pasien, riwayat pasien pulang, apgar bayi, status bayi, surat pengantar pemeriksaan laboratorium, dan hasil laboratorium.

Desain aplikasi sistem yang baru di buat dengan rencana yang matang sehingga membutuhkan biaya perencanaan yang berjumlah sebesar Rp 1.995.000,-. Terlihat perbedaan jumlah biaya antara sistem lama dan baru yang cukup signifikan. Pada sistem lama jumlah yang dikeluarkan dalam jangka waktu setahun adalah Rp 82.195.200,- sedangkan sistem baru dalam jangka waktu enam bulan (siklus satu tahun) adalah Rp 41.877.675,-. Biaya yang dihasilkan pada sistem baru terlihat lebih rendah daripada sistem lama karena terdapat pengurangan pemakaian alat tulis kantor seperti kertas, tukang servis komputer, dan instal ulang komputer. Walaupun demikian, bila di hitung dalam jangka waktu satu tahun terlihat cukup besar biaya pada sistem baru. Hal itu dikarenakan pada tahun pertama sistem yang baru terdapat biaya analisis dan desain, biaya instalasi, biaya implementasi, dan biaya lain-lain yang besar nilainya. Biaya tersebut sangat mencolok di tahun pertama tetapi untuk tahun selanjutnya dapat meminimalisasi biaya penggunaan kertas dan menciptakan peluang adanya penambahan nilai (value-added) terhadap sistem yang baru.

\section{DAFTAR PUSTAKA}

Badan Pusat Statistik. (2016). Data Pertumbuhan Klinik di Provinsi Jawa Barat. 7 Maret, 2016, http://jabar.bps.go.id/Subjek/view/id/30\#subjekViewTab1|accordion-daftar-subjek1

Bodnar, G \&William, S. (2006). Sistem Informasi Akuntansi.Ed. Kesembilan. Yogyakarta : Andi. Kementerian Kesehatan. (2013). Badan Penyelenggara Jaminan Kesehatan.

Noor.(2011). Implementasi Sistem Informasi Rumah Sakit untuk Subsistem Farmasi. Jurnal Seminar Tugas Akhir.

Peraturan Menteri Kesehatan Nomor 138 Tahun 2009 tentang Rawat Inap.

Peraturan Menteri Kesehatan Nomor 28 Tahun 2011 tentang Klinik.

Peraturan Menteri Kesehatan Nomor 560 Tahun 2003 tentang Tarif Rumah Sakit.

Romney, M \& Steinbart, P. (2014). Sistem Informasi Akuntansi. Buku Kesatu. Ed. Kesembilan. Jakarta : Salemba Empat.

Tebiary, An Apriyani., Suastika, Ketut.,\& Ma'aruf, B. (2017). Analisis Non Value Added Activity pada Proses Produksi Kapal dengan Pendekatan Value Stream Mapping. Jurnal Wave, 11(1).

Undang - undang Nomor 29 Tahun 2004 tentang Praktek Kedokteran.

Analysis of Development Costs and ValueAdded Accounting Information Systems on Road and Inpatient Services at Cribs and Gebang 